$$
\begin{aligned}
& V-12 \\
& B E H \\
& M O .5 \cdot 9
\end{aligned}
$$

Standards Stor Engineeviy Economy notation

MAR. 82

JUL. 221977 

and Marine Engineering

University of M1chigan

450 West Engineering Building

Ann Arbor, Michigan

$v-12$

STANDARDS् FOR ENGINEERING ECONOMY NOTATION

by

Harry Benford 



\title{
STANDARDS FOR ENGINEERING ECONOMY NOTATION
}

\author{
by Harry Benford
}

The Engineering Ecomony Division of the American Society for Engineering Education is preeminent in the United States in publishing papers on engineering economics. In response to a long-felt need, that group has recently adopted a set of recommended standards for the symbols and abbreviations used in engineering economics. Those recommendations are published in The Engineering Economist, Vol. 12, No. 4 (1967).

I should like to propose that authors in the marine industry follow those standards. The accompanying tables summarize the most common concepts and interest relationships. For convenience, the new terms and symbols are paralleled by a column of older forms now found in marine literature. I purposely have omitted reference to several complicated concepts that are of little use in ship economics studies. I have deleted gradient cash flows, continuous compounding, and nonannual periodic compounding. For ship design purposes, we can almost always assume annual compounding and interest rates on a per-year basis. I have also omitted a second, alternative set of forms for indicating the interest factor, interest rate, and number of compounding periods. I did this because the alternative set proposed closely resembles the old forms already familiar to the marine industry.

The new standards use lowercase letters for rates, ratios, and indices. Uppercase letters are used for absolute values, notably time, and sums of money. The form for indicating interest factor, interest rate, and number of periods omits subscripts and superscripts--thus easing the typist's lot and eliminating a fertile source of mistakes. 
TABDE I

DEFINITIONS AND SYMBOLS FOR PARAMEHERS

\begin{tabular}{|c|c|c|}
\hline \multirow[t]{2}{*}{ Definitions } & \multicolumn{2}{|c|}{ Symbols } \\
\hline & Old & Hew \\
\hline Effective interest rate per interest period & $\dot{1}$ & $\grave{i}$ \\
\hline Number of compounding periods & $\mathbf{n}$ & F \\
\hline $\begin{array}{l}\text { Present sum of money, or present value (or } \\
\text { a single imvestment) }\end{array}$ & $\mathbf{P}$ & $\mathbf{P}$ \\
\hline Future sum of money & $\mathbf{S}$ & F \\
\hline $\begin{array}{l}\text { End-of-period cash flows (or equivalent end- } \\
\text { of-period values) in a uniform series } \\
\text { continuing for a specified number of pe- } \\
\text { riods. The letter A implies annual or } \\
\text { annuity. }\end{array}$ & $\mathrm{R}$ & A \\
\hline
\end{tabular}


TABLE II

SINGLE PAYMENT, COMPOUND AMOUNT RELATIONSHIPS

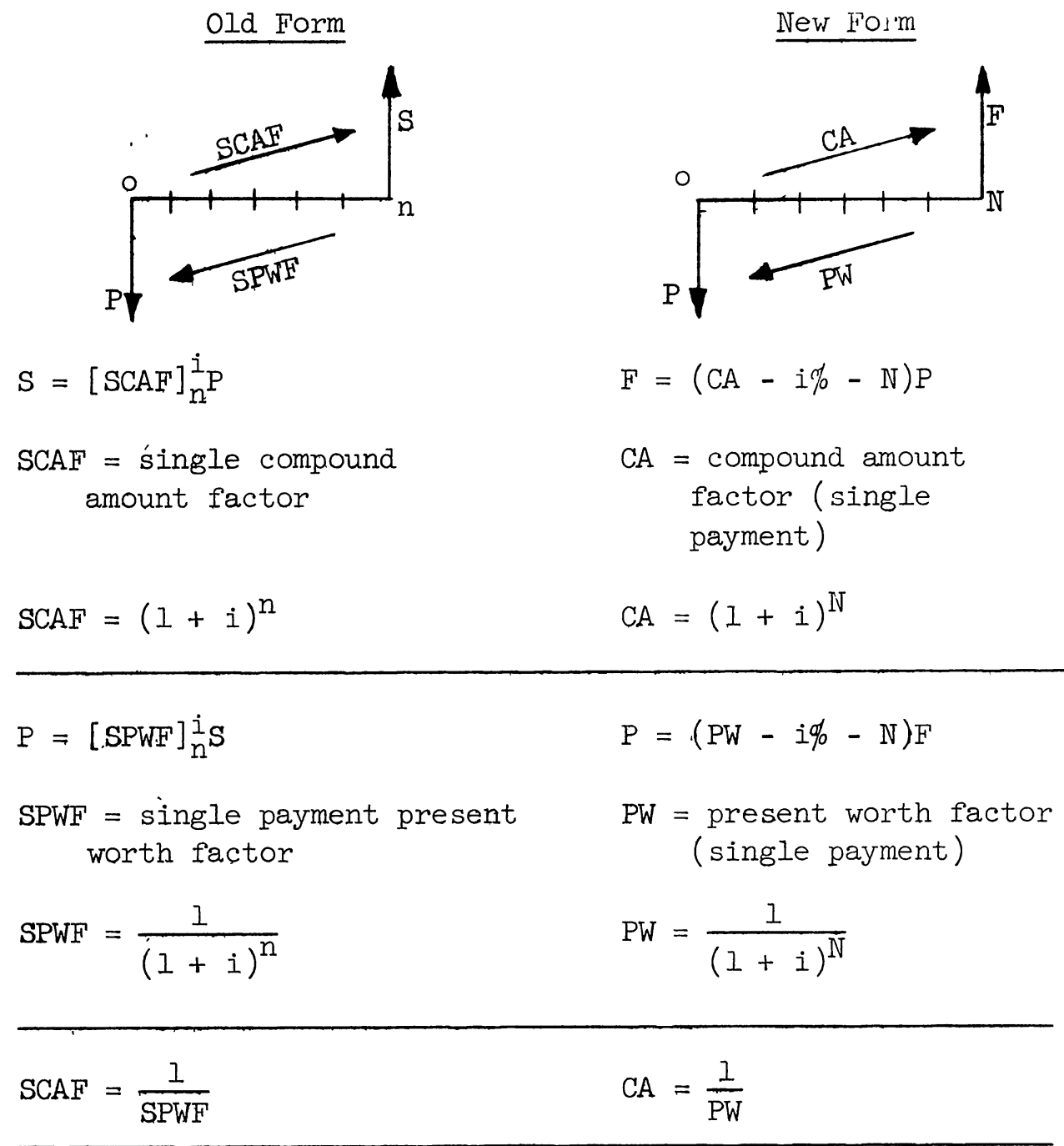


UNIFORM SERIES, COMPOUND AMOUNT RELATIONSHIPS
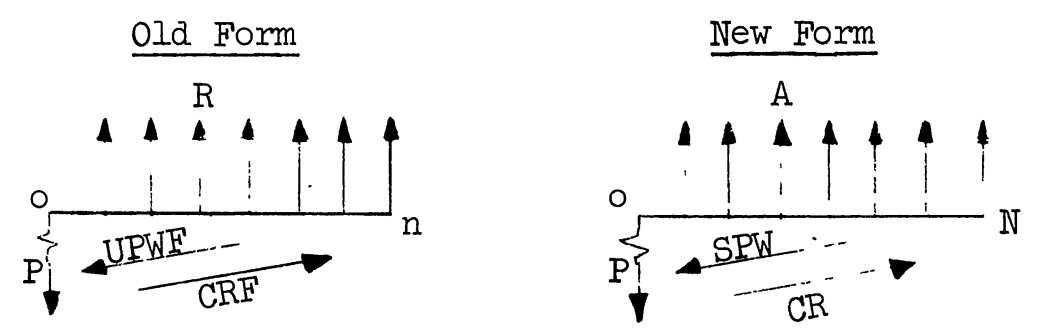

$$
\begin{aligned}
& P=[U P W F]_{n}^{i} R \\
& \text { UPWF = uniform present worth } \\
& \quad \text { factor }
\end{aligned}
$$$$
P=(S \ddot{P W}-i \%-N) A
$$$$
\text { SPW }=\text { series present worth }
$$
factor

$U P W F=\frac{(1+i)^{n}-1}{i(1+i)^{n}}$ $\mathrm{SPW}=\frac{(1+i)^{\mathrm{N}}-1}{i(1+i)^{\mathbb{N}}}$

$\mathrm{R}=[\mathrm{CRF}]_{\mathrm{n}}^{\mathrm{i}_{\mathrm{P}}}$

$A=(C R-i \%-N) P$

$\mathrm{CRF}=$ capital recovery factor

$\mathrm{CR}=$ capital recovery factor

$\mathrm{CRF}=\frac{i(1+i)^{\mathrm{n}}}{(1+i)^{\mathrm{n}}-1}$

$C R=\frac{i(1+i)^{N}}{(1+i)^{\mathbb{N}}-1}$

$\mathrm{UPWF}=\frac{1}{\mathrm{CRF}}$

$$
\mathrm{SPW}=\frac{1}{\mathrm{CR}}
$$



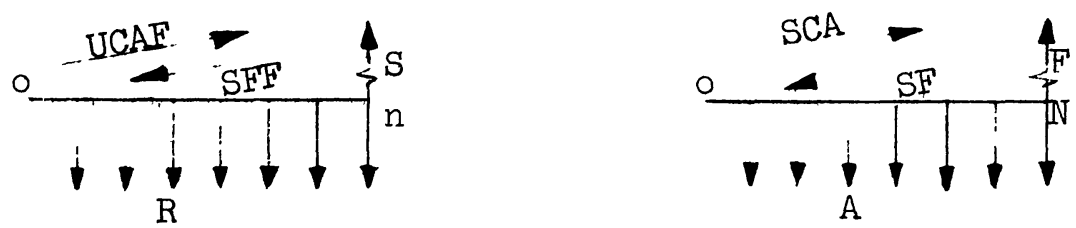

$S=[U C A F]_{n}^{i} R$

$F=(S C A-i \%-N) A$

UCAF = uniform compound amount factor

$\mathrm{SCA}=$ series compound amount factor

$\mathrm{UCAF}=\frac{(1+i)^{\mathrm{n}}-1}{i}$

$\operatorname{SCA}=\frac{(I+i)^{N}-\perp}{i}$

$\mathrm{R}=[\mathrm{SFF}]_{\mathrm{n}}^{i} \mathrm{~S}$

$\mathrm{SFF}=$ sinking fund factor

$S F F=\frac{i}{(1+i)^{n}-1}$

$\mathrm{UCAF}=\frac{1}{S F^{\prime}}$
$A=(S F-i \%-N) F$

$\mathrm{SF}=$ sinking fund factor

$S F=\frac{i}{(1+i)^{N}-1}$

$\mathrm{SCA}=\frac{1}{S \mathrm{~S}}$ 

UN

$\sqrt{39015} 087358910$

DATE DUE

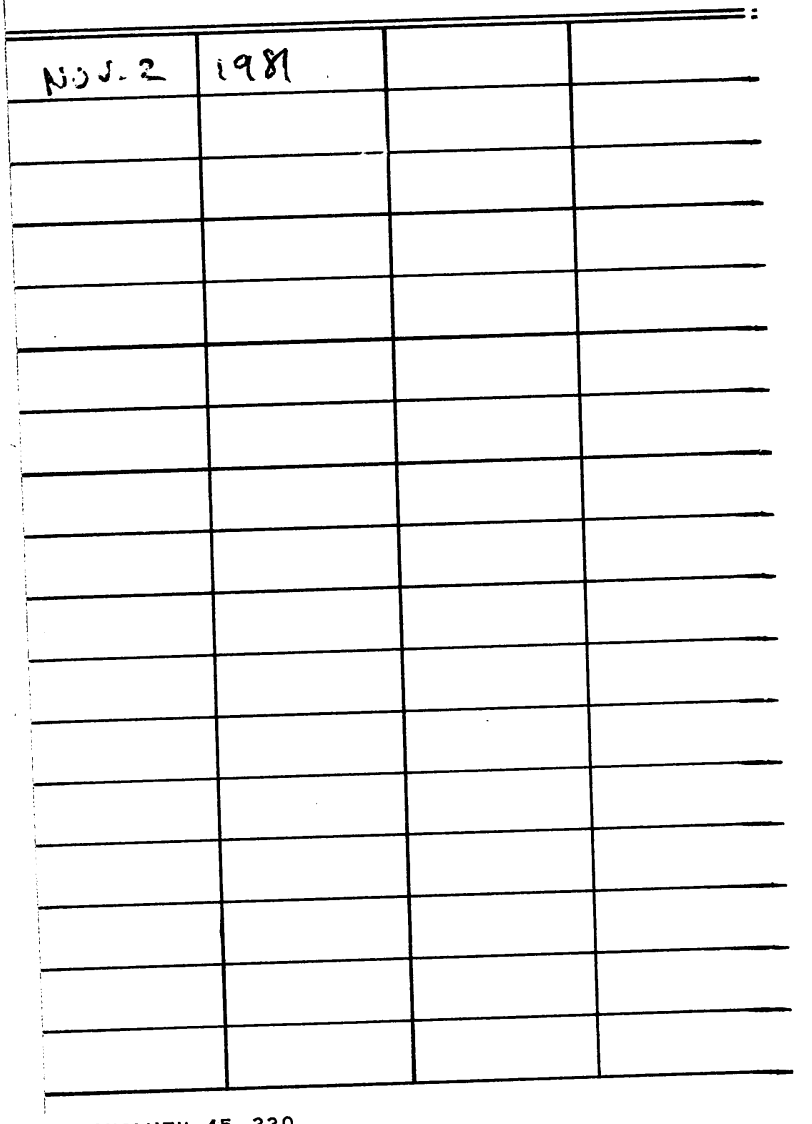


